\title{
Experimenting with imposters: What modulates choice of person agreement in pronouns? ${ }^{1}$
}

\author{
Elsi KAISER - University of Southern California \\ Justin NICHOLS - University of Southern California \\ Catherine WANG - University of Southern California
}

\begin{abstract}
Imposters are grammatically third-person expressions used to refer to the firstperson speaker or second-person addressee (e.g. 'the present authors' when used to refer to the first-person writer, 'Mommy' or 'Daddy' when used by parents for self-reference in child-directed speech). Current analyses of imposters differ in whether they derive the unusual referential properties of imposters using syntactic means or attribute them to semantic and pragmatics. We aim to shed light on these competing approaches by means of a psycholinguistic experiment focusing on first-person imposters that investigates the kinds of pronouns (first-person vs. third-person) used to refer to imposter antecedents. Our results show that manipulating the prominence of the first-person speaker does not significantly boost the acceptability of first-person pronouns in imposter-referring contexts. However, our results suggest that a purely syntactic approach may not be sufficient either, as psycholinguistic processing factors also appear to be relevant.
\end{abstract}

Keywords: person agreement, agreement mismatch, pronoun, imposters, psycholinguistics, accessibility, prominence.

\section{Introduction}

Language often draws a sharp distinction between speaker, addressee and others in terms of the grammatical category of person. However, sometimes this neat division breaks down and third-person expressions are used to refer to the speaker or the addressee. This phenomenon is illustrated in $(1 a, b)$, where the speaker refers to themselves with expressions like 'Grandma' and 'this reporter.' These expressions occur with third-person verb agreement in English, but their intended interpretation is the first-person $I$ (speaker).

(1) a. Grandma needs to rest a bit! (said by grandmother to daughter)

b. At the time, CBS News and this reporter fully believed the documents were genuine.

(Dan Rather, talking about himself, from Collins and Postal, 2012:1)

These elements are often called imposters, which are defined by Collins and Postal (2012) as notionally first- or second-person DPs that are grammatically third person. More generally, an imposter can be defined as "A notionally $\mathrm{X}$ person DP that is grammatically $\mathrm{Y}$ person, $\mathrm{X} \neq \mathrm{Y}$ ” (Collins and Postal, 2012:5). Thus, imposters' grammatical person does not match their semantic or notional person (see also Collins, 2014 for a crosslinguistic discussion of imposters in a variety of languages).

\footnotetext{
${ }^{1}$ Many thanks to the audience at Sinn und Bedeutung for useful comments and feedback. We are grateful for funding from the Undergraduate Research Associates Program at the University of Southern California.
} 
First-person and second-person imposters in English occur in a variety of contexts and registers, as exemplified in (1-3). As the examples show, imposters occur both in informal child-directed speech and in the more formal academic register. This phenomenon is not confined to a particular register.

\section{(2) First-person imposters}

a. At the same time, the present authors had been asking ourselves whether there should be a model of cooperative governance (www.grocer.coop)

b. The undersigned authorizes my student to participate in authorized DoDEA school study trips... (DoD Education Activity form)

c. ...the emphasis on restoring functions, as opposed to designing projects around the benefits themselves, seems sensible and appropriate to this reviewer. From my limited perspective... (http://tahoe.ca.gov/)

\section{(3) Second-person imposters}

a. Would little Jimmie like another ice-cream cone? (Collins and Postal, 2012:7)

b. How is my darling tonight? (Collins and Postal, 2012:7)

The structure of this paper is as follows: In Section 2, we review two competing views of imposters that differ in terms of how much of imposters' unusual behavior is attributed to syntax vs. semantics and pragmatics. In Section 3, the person agreement properties of English singular and plural imposters are discussed. As we will see, English plural imposters can antecede both first- and third-person pronouns and reflexives, whereas singular imposters, at least in some contexts, appear to be limited to third-person pronouns. To further assess the acceptability of first- and third-person pronouns with imposter antecedents and to see whether increasing the prominence of the first-person speaker referent boosts the acceptability of firstperson pronouns, we conducted a psycholinguistic experiment. The method and design are presented in Section 4, and the results are discussed in Section 5. Section 6 concludes the paper.

\section{Two views of imposters}

The split between imposters' grammatical and notional properties-the fact that they seem to be grammatically third-person, at least when it comes to verb agreement in English, while being notionally first- or second person-poses challenges for theories of agreement. How can we capture this two-faced behavior of imposters? Broadly speaking, prior work has attributed the unexpected behavior of imposters either to (i) special syntactic properties of imposter DPs-what Collins and Postal (2012) call the syntactic view-or (ii) to special semantic or pragmatic properties of imposters-what Collins and Postal call the notional view.

One possibility is that imposters are syntactically normal third-person DPs (e.g. Baker, 2008; Siewierska, 2004; see also Stirling and Huddleston, 2002). Under this view, these grammatically third-person DPs are special in their interpretational/referential component, since they can refer to a first- or second-person referent. Under this view, any special agreement properties that imposters exhibit must stem from somewhere other than syntaxe.g. semantics / pragmatics / discourse-because syntactically, they are the same as normal 
(non-imposter) third-person DPs. Collins and Postal (2012) refer to this approach as the notional view, and summarize it as follows:

(4) Notional view: "Imposters are syntactically regular 3rd person DPs with the semantic/discourse property that they denote either the speaker(s) (in the same sense as 1 st person pronouns do) or the addressee(s) (in the same sense that 2 nd person pronouns do)." (2012:78, emphasis in original)

Baker (2008) discusses examples like (5a,b) and states that "ordinal non-pronominal DPs are never first or second person, even when they refer to the speaker or hearer" (p.126).

a. $\quad\left[\mathrm{CP} \mathrm{S}_{\mathrm{i}}[\mathrm{TP}[\mathrm{NPi}\right.$ The man who is/*am talking to you $]$ is hoping to get some money. b. $\quad$ Sorry honey, but Daddy is/*am too tired to play with you tonight.

According to Baker, a speaker-referring, first-person imposter like 'the man who is talking to you' can have the same index as the speaker (which he denotes with $\mathrm{S}$ in 5a). However, he describes this as "a definite description that refers to the speaker without being dependent on S" (Baker, 2008:127). In essence, under his account, imposters can refer to the speaker (i.e., can have the same index as the speaker) but are syntactically normal third-person DPs.

Using examples like (6a,b), Siewierska (2002) notes that expressions like 'mummy' and 'Johnny' can be used to refer to the speaker and the addressee, "but they cannot be said to express the discourse roles of speaker and addressee, as there is nothing in the words mummy and Johnny to suggest that they are speaker and addressee respectively" (Siewierska. 2002:2). She continues that "only I and you and not mummy and Johnny are expressions of the first and second persons" (Siewierska, 2002:2). Thus, according to Siewierska, imposters are grammatically third person, similar to Baker's view (see also Stirling and Huddleston, 2002).
a. I will spank you.
b. Mummy will spank Johnny.

Siewierska notes that "In principle, there is no limit to the nature of the lexical expressions that a speaker may use to refer to herself' (Siewierska, 2002:2). However, Collins and Postal (2012) note that it is not the case that any third person DP can freely be interpreted as speaker-referring (or addressee-referring). For example, in (7a-b), 'Uncle Carl' cannot be an imposter, whereas in (7c) it can be interpreted as a first-person (speaker-referring) imposter. Thus, an open question for the notional view is what determines whether a DP can be interpreted as an imposter or not-in other words, what are the constraints that ensure that Uncle Carl can be interpreted as an imposter in (7c) but not in (7a-b).
a. Are you Uncle Carl?
b. Uncle Carl is my neighbor.
c. Uncle Carl really needs to take a nap.

Collins and Postal (2012) argue against the notional view of imposters, and in favor of an analysis where the behavior of imposters stems from special syntactic properties. Under this view, the behavior of imposters is syntactically determined, and not due to semantics or 
discourse (see also Collins, 2014). Simplifying considerably, the basic idea is that imposter DPs are structurally complex and include null indexical first (or second) person pronouns, in addition to the overt (visible) third-person DP. This plays a crucial role in allowing imposters to antecede both first-person and third-person pronouns, as exemplified in (8). Here, it seems that both themselves and ourselves are grammatical-i.e., the syntactically third-person imposter can antecede either a first-person or a third-person reflexive pronoun. (We discuss these patterns more in Section 3).

(8) Said by father to child:

Not now! Ask Auntie Jane to show you the garage. Daddy and Uncle Jim are enjoying \{themselves/ourselves\} on the beach. (adapted from Collins and Postal 2012)

More specifically, Collins and Postal (2012) analyze imposters as being derived from appositive precursor structures such as 'we, the present writers' or 'I, your faithful correspondent', such that imposter DPs have a null 'core' DP that expresses the notional first (or second) person pronoun as well as a visible DP that expresses the third-person form. For the purposes of the present paper, we assume that imposters (under the syntactic view) are indeed structurally complex, but the exact nature of that structure is not crucial for the claims we are making here.

A full summary of Collins and Postal's system is beyond the scope of this paper, but crucially, it is a syntactically-defined system: The tension between the grammatical and notional person patterns of imposters is encoded in the structure of the imposters themselves by means of a covert indexical, and the person agreement patterns (Section 3) are derived by means of the syntactic notion of antecedence and the possibility of agreeing with both primary and secondary sources (syntactically defined).

\section{Person agreement with imposters: Reflexives and possessive pronouns}

Although English imposters consistently trigger third-person verb agreement (5), the person agreement patterns-as exhibited by reflexives and possessive pronouns-are less consistent. Specifically, it seems that plural imposters (e.g. the present authors) or coordinated imposters (e.g. Mommy and Daddy) can antecede both third- or first-person pronouns and reflexives, whereas singular imposters can only antecede third-person pronouns and reflexives (see also Collins and Postal, 2012; Collins et al., 2009; for a crosslinguistic overview, see Collins, 2014).

Let us first consider the data for plural imposters. As shown in (9), both third-person and first-person possessive pronouns and reflexives seem to be acceptable. In all cases in this paper, the intended interpretation is the one where the relevant pronoun or reflexive is coreferential with the imposter (i.e., does not refer to a third person). The possibility of using either first- or third-person reflexives is available with both 'regular' reflexives (9c) as well as inherent reflexives (9b). (We focus here on speaker-referring imposters and first-person pronouns, but the same observations and questions arise with addressee-referring imposters and second-person pronouns.) 


\author{
a. Said by father to child: \\ Mommy and Daddy need to take \{their/our\} shoes off first! \\ b. Said by father to child:
}

Not now! Ask Auntie Jane to show you the garage. Daddy and Uncle Jim are enjoying \{themselves/ourselves\} on the beach. (adapted from Collins and Postal 2012:114)

c. Said/written by authors:

In this reply, the present authors attempt to defend \{themselves/ourselves\} against the scurrilous charges which have been made (Collins and Postal 2012:vii)

Based on the first/third person alternation that is allowed by plural imposters, we might expect singular imposters to show the same flexibility when it comes to pronoun person agreement. However, the situation is less clear than one might expect. Collins and Postal note that singular imposters (e.g. Daddy, this reviewer) seem to require third person pronouns and reflexives. They report that first person pronouns and reflexives sound worse in these contexts. $^{2}$ This intuition is supported by a small-scale experiment with fifteen participants conducted by Collins, Guitard and Wood (2009).
a. Said by father to child:
Daddy needs to drink $\{$ his/*my coffee first!
b. Said by father to child:
Not now! Ask Auntie Jane to show you the garage. Daddy is enjoying
$\{$ himself/*myself $\}$ on the beach. (adapted from Collins and Postal, 2012)
c. Said by a speaker who refers to himself as 'this reporter':

This reporter sees himself/*myself as a managing editor in the future. (Collins and Postal, 2012:20)

However, as Collins and Postal (2012:20-21) acknowledge, there are also naturally-occurring examples from the web where singular posters antecede first-person anaphors, as illustrated in (11) (Examples cited by Collins and Postal, 2012).

(11) a. This reviewer found myself frustrated at times with the various storylines (from an Amazon review)

b. while yours truly treated myself to a few ice cold Miller Lites (from sportingnews.com)

c. This reporter sent myself to cover Bill Clinton's lecture at the Dorothy Pavilion (from www.louisepalanker.com)

Furthermore, Baker $(2008: 128)$ suggests that the acceptability of first-person pronouns with singular imposters may depend on whether imposter c-commands the pronoun. In the absence

\footnotetext{
2 Collins \& Postal distinguish imposters from what they call 'camouflage DPs' (see also Collins, Moody \& Postal, 2008). One subclass of camouflage DPs are Social Hierarchy Camouflage Constructions such as your majesty, your honor. Collins \& Postal (2012:74) note that in SHCC, the notional core is overt and occurs in possessor position: In your majesty, for example, the notional core is the second person addressee you (compare to yours truly or my lord, where the possessive pronoun does not match the notional referent). It seems that unlike imposters, camouflage DPs easily allow person alternation in the singular as well (ex.i). A discussion of why this is possible with camouflage DPs is beyond the scope of the present paper.
}

(i) [Your majesty] $]_{i}$ should praise yourself ${ }_{\mathrm{i}} /$ herself $_{\mathrm{i}}$. (Collins, 2014:1) 
of c-command, he reports that singular imposters can antecede first-person pronouns, and described (12a) with the first-person pronoun as "more or less possible" (p.128):

(12) a. Father says: Because Daddy ${ }_{\mathrm{k}}$ forgot something at the office, he $\mathrm{k}_{\mathrm{k}}$ has/I $\mathrm{I}_{\mathrm{k}}$ have to go back there.

b. Father says: Daddy $\mathrm{k}_{\mathrm{k}}$ has to go back to the office because $\mathrm{he}_{\mathrm{k}} / \mathrm{I} *_{\mathrm{k}}$ forgot something there.

Thus, it is not yet well-understood (i) whether-or under what conditions and what syntactic configurations-singular imposters can antecede first-person pronouns, and (ii) why plural imposters seem to be able to antecede first-person pronouns more easily than singular imposters. Collins (2014) notes that "the singular/plural asymmetry with imposters remains a mystery, and accounting for it is one of the greatest challenges for future work" (Collins, 2014:24, see also Podobryaev, 2014; 2017 for related discussion of an asymmetry in the person feature assignment of plural vs. singular personal pronouns). Before considering the behavior of singular imposters in more depth, we consider how, according to Collins and Postal (2014), plural imposters can exhibit both first- and third-person agreement.

\subsection{Multiple agreement options with plural imposters}

How can plural imposters in English antecede both first- and third-person pronouns? Collins and Postal note that it is unclear how the notional view can capture these agreement patterns: If imposters are syntactically regular third-person DPs, it is unclear how they can bind firstperson reflexive pronouns, ${ }^{3}$ if we assume that reflexives agree with their antecedents in terms of $\varphi$-features.

According to Collins and Postal (2012)'s syntactic view, the pronominal agreement patterns stem from the availability of more than one possible antecedent in the syntactic structure. They propose, building on prior work, that the left periphery contains null DPs for AUTHOR (aka Speaker) and ADDRESSEE. The AUTHOR DP is first person, and can be singular or plural (depending on the situation), and, correspondingly, the ADDRESSEE DP is second person, and can also be singular or plural. The AUTHOR and ADDRESSEE DPs are represented in an expanded left periphery (Rizzi 1997) or as arguments of a covert performative clause (Collins 2014, see also Speas and Tenny, 2003; Haegemann and Hill, 2013 on the Speech Act Projection). These null DPs are present even if the sentence does not contain first or second person pronouns. ${ }^{4}$

Crucially, to capture agreement patterns such as those in (9), Collins and Postal claim that a pronoun can agree with a primary or a secondary source. A full summary of their analysis is beyond the scope of this paper, but in essence, in (13), a pronoun can agree with (i)

\footnotetext{
${ }^{3}$ Unlike the clear distinction between anaphoric vs. pronominal forms that is visible on object-position nominals (e.g. herself vs. her), English possessive pronouns do not morphologically distinguish reflexive and nonreflexive configurations, in contrast to languages like Swedish (see also Kuno, 1987:80 for discussion).

${ }^{4}$ However, some researchers argue against the syntactic encoding of speech-act-participant related projections at the left periphery (see e.g. Gärtner \& Steinbach, 2006). In order to argue for a purely syntactic approach to imposters, the representation of AUTHOR (speaker) and ADDRESSEE presumably needs to be syntactically encoded, so when discussing the syntactic view we treat them as null DPs in the left periphery.
} 
AUTHOR as its ultimate antecedent, yielding first-person our (ex.13a) or ourselves (ex.13b) or with (ii) its immediate antecedent 'Mommy and Daddy, yielding third-person their (ex.13a), or themselves (ex.13b). In this system, both the ultimate and immediate antecedent are defined as sources in configurations like (13) and thus pronominal agreement with either one is possible.

In contrast to proponents of the notional view, Collins and Postal claim that all pronouns (except expletives) have linguistic antecedents (Collins, 2014:4)-i.e., a first-person form like 'our or 'ourselves' in (13) does not, under their approach, refer to an extra-linguistic referent but instead has a syntactically-present antecedent.

(13) a. [[DP AUTHOR] Mommy and Daddy need to finish \{their/our\} coffees first.]] b. [[DP AUTHOR] Mommy and Daddy are enjoying \{themselves/ourselves\} on the beach.]]

\subsection{Choosing between multiple agreement options}

The observation that plural imposters seem compatible with both first and third person agreement raises the question of what influences the choice of one over the other. Collins and Postal do not address this question in detail, and Akkuş (2017) notes that the choice of first vs. third-person pronoun does not correlate with truth-conditional differences. Indeed, if we assume a purely syntactic view of imposters, then both agreement options-(i) agreement with the ultimate AUTHOR antecedent and (ii) agreement with the immediate linguistically-overt third person antecedent-are equally available, as both are syntactically possible.

However, prior work on the general topic of pronoun use and interpretation (albeit mostly in in cross-clausal contexts with multiple possible antecedents) suggests that differences in antecedent accessibility/prominence guide pronoun interpretation. More specifically, many researchers have suggested that referents which are cognitively more accessible/prominent in language users' minds at a particular point in the discourse are more likely to be chosen as antecedents of pronouns (e.g. Ariel, 1990; Gundel et al., 1993, and many others). Even though multiple referents can be activated in people's mental representations of the discourse, some are more highly activated than others. Work on pronoun interpretation suggests thatother things being equal-pronouns tend to be interpreted as referring to the most salient referents. ${ }^{5}$ This might lead one to expect that in imposter structures such as (13), the pronoun will tend to agree with whichever antecedent-the ultimate AUTHOR (speaker) antecedent or the immediate 'Mommy and Daddy' antecedent-is more prominent.

But what influences the prominence/accessibility of potential antecedents? Work on crosssentential pronoun interpretation has identified multiple factors, including (i) recency of mention (e.g. Givón, 1983)-more recently mentioned entities are more accessible/prominent than less-recently mentioned ones-as well as (ii) syntactic prominence-referents realized in subject position are more accessible/prominent than referents in other syntactic positions (e.g.

\footnotetext{
${ }^{5}$ The salience/accessibility-based patterns observed in the pronoun resolution literature are gradient preferences and biases, not absolute principles or requirements.
} 
Brennan et al., 1987). Various other factors such as verb semantics and discourse coherence have also been identified.

We conducted a psycholinguistic experiment designed to manipulate the prominence of the AUTHOR-in other words, the speaker of the sentence-to see if this influences people's preference for first-person pronouns. We tested sentences where the main clause was (or was not) preceded by a subordinate clause-which we will call the 'preamble'-that explicitly mentions the speaker(s) in subject position by means of a pronoun (ex.14).

(14) a. Mommy and Daddy have to finish \{ $\underline{\text { our }} \underline{\text { their }}\}$ coffees.

b. Before we take you to daycare, Mommy and Daddy have to finish \{ $\underline{\text { our/their }}$ \} coffees.

In light of prior work showing that pronouns prefer prominent antecedents, combined with findings showing that recency of mention and realization in subject position boost referent prominence, we might expect first person pronouns to be more likely in (14b) than in (14a)or in terms of acceptability, we may find that participants rate (14b) with our as more acceptable or natural than (14a) with our. Third-person pronouns are presumably equally acceptable in both contexts, as they match the grammatical third-person status of the imposter.

\subsection{Singular imposters: Acceptability of first-person vs. third-person pronoun}

In addition to testing plural imposters (ex.14a,b), we also investigated singular imposters, to gain more clarity into whether they can antecede first-person pronouns in addition to thirdperson pronouns. Collins and Postal (2012) report first-person pronouns as being ungrammatical with singular imposters, but acknowledge that corpus examples with firstperson pronouns exist (see (11)). A small-scale study by Collins et al. (2009) tested an item in a configuration where a possessive first- or third-person pronoun (in an idiomatic, inalienable-possession construction, 'lose my/his cool') refers to a singular imposter ('this reporter') and obtained an average rating of 1.573 out of a maximum rating of 3 . Although it is not yet clear if this pattern will generalize to other sentences and other types of possession relations, it further highlights the unclear status of pronoun patterns with singular imposters. In addition, Baker (2008) notes that presence vs. absence of c-command may play a role. In sum, the status of singular imposters anteceding first-person pronouns in English is not clear.

Thus, we investigated whether the presence of a preamble clause that mentions the AUTHOR by means of the first-person pronoun "I" in subject position makes first-person pronouns more acceptable in sentences like (15). If the choice of a first-person vs. third-person pronoun is modulated by the accessibility/prominence of the first-person AUTHOR-a prediction compatible with the notional view but one that does not follow from the syntactic view-we expect to effects of the presence/absence of the preamble clause.

(15) a. Mommy has to finish $\{\underline{\mathbf{m y} / \mathbf{h e r}}\}$ coffee.

b. Before I take you to daycare, Mommy has to finish $\{\underline{\mathbf{m y}} / \underline{\mathbf{h e r}}\}$ coffee. 


\section{Experiment}

We conducted an acceptability-rating experiment to investigate (i) whether the acceptability of first-person vs. third-person pronouns with third-person imposters is modulated by the prominence/salience of the AUTHOR antecedent and to (ii) test whether singular imposters can antecede both first- and third-person pronouns and (iii) whether this is influenced by the prominence of the AUTHOR antecedent. We tested the acceptability of first-person and third-person possessive pronouns with plural and singular imposter antecedents, with and without preamble clauses that mention the AUTHOR by means of an overt first-person pronoun.

We tested possessive pronouns rather than reflexive pronouns, because it was easier to generate a large number of target sentences with possessives without needing to use lowerfrequency or more marked verbs which might inadvertently catch participants' attention or sound unusual for reasons orthogonal to imposters. In all of our critical sentences, the imposter NP c-commands the possessed noun, as shown in (13-14). ${ }^{6}$

\subsection{Method}

\subsubsection{Participants}

Forty adult native English speakers from the University of Southern California community participated.

\subsubsection{Materials and design}

We manipulated (i) number (singular and plural imposters and pronouns), (ii) person (first and third person pronouns) and (iii) context (presence/absence of preamble clause that mentions the speaker/AUTHOR). The subject of the sentence was either a singular thirdperson imposter (e.g. Mommy, Grandpa) or a coordinated DP yielding a plural (e.g. Mommy and Daddy). Thus, the plurals we tested were all coordinated structures. The possessive pronouns were correspondingly either singular or plural-and, crucially, either first-person ( $m y$, our) or third person (her/his, their). In addition to manipulating person and number, we also manipulated the context-specifically, whether or not the main clause was preceded by a temporal clause containing a first-person pronoun $(I$, we) that refers to the speaker (AUTHOR). This yields a $2 \times 2 \times 2$ design ( 8 conditions, presented with a standard LatinSquare design). The experiment included 32 target items and 36 filler items. The imposters used in targets and fillers included terms referring to parents (Mom, Dad, Mommy, Daddy) and grandparents (Grandma, Grandpa).

\footnotetext{
${ }^{6}$ As mentioned above, Baker (2008) suggests that configurations where the imposter does not c-command the pronoun may be more likely to allow first-person pronouns with third-person imposters. We did not investigate non-c-command configurations in our work, and leave this as a question for future research.
} 
In this experiment, we used parent- and grandparent-referring imposters in child-directed speech. This is because pre-testing showed that college-aged U.S. English speakers (i.e., the group that our participants belong to) are familiar with this type of imposter use. In future work, we plan to explore imposters in more formal academic registers, such as "the present authors," after ensuring that we can identify enough participants familiar with this usage.

All targets and fillers were preceded with information about who says the sentence to whom, as illustrated in (16). This is important as it ensures that the relevant nouns are interpreted as imposters, rather than 'normal' nouns referring to third-person, non-speaker referents. To encourage participants to attend to the clause indicating who says the sentence, they were asked open-ended recall questions during the experiment about who said the preceding sentence, and had to answer these questions without seeing the sentence again.

(16a) NoContext_SG_3

Father says to child:

Daddy has to finish his coffee.

NoContext_SG 1

Father says to child:

Daddy has to finish $\underline{\text { my }}$ coffee.

(16b) Context_SG_3

Father says to child:

Before I take you to daycare, Daddy has to finish $\underline{\text { his }}$ coffee.

NoContext_SG_1

Father says to child:

Before $\underline{\mathbf{I}}$ take you to daycare, $\underline{\mathbf{D a d d y}}$ has to finish $\underline{\mathbf{m y}}$ coffee.

(16c) NoContext PL 3

Father says to child:

Daddy and Mommy have to finish their coffees.

NoContext_PL_1

Father says to child:

Daddy and Mommy have to finish our coffees.

(16d) Context_PL_3

Father says to child:

Before we take you to daycare, Daddy and Mommy have to finish their coffees.

Context_PL_1

Father says to child:

Before we take you to daycare, Daddy and Mommy have to finish our coffees.

When designing the stimuli, we aimed to minimize the likelihood that a first-person plural possessive could be construed as referring to possession involving the addressee (child) in 
addition to the parents/grandparents. This is important, because we want to probe whether first-person pronouns can be anteceded specifically by the imposter. Thus, we wanted to avoid situations where the addressee is also one of the possessors, as this could trigger use of first-person plural 'our,' as illustrated in (17).

(17) Anne says to Beth: Carla needs to pack our Anne's + Beth's bags.

Thus, we used possessives such as 'their/our coffees' or 'their/our work shirts'-i.e., things that are likely to be possessed only by the parents or grandparents-and tried to avoid joint family objects such as 'our car' or 'our house' whose ownership could also involve the child.

In addition to 32 targets, the study also included 36 filler items. The fillers were also presented as said by a parent or grandparent to a child, and some of them also contained imposters. However, unlike targets, the fillers did involve possessive constructions where the possessor refers to the imposter. The fillers were designed to elicit a range of acceptability judgments.

\subsubsection{Procedure}

Investigating coreference judgements by means of psycholinguistic experiments with naïve participants can be challenging. The term 'coreference' is not familiar to non-linguists, and introducing notation such as coindexing can be confusing. In our experiments, we build on the seminal paper of Gordon and Hendrick (1997). They report a series of six experiments on Binding Theory that investigate the coreference judgments of native English speakers who are "naïve to contemporary syntactic theory" (Gordon and Hendrick, 1997:325). Following Gordon and Hendrick, we presented our participants with sentences where certain words were bolded and underlined, ${ }^{7}$ and asked them to rate the acceptability of the sentence when those two words refer to the same person or thing. On target trials, the subject, the possessive pronoun and, if a preamble clause was present, the first-person pronoun in preamble, were bold and underlined. (See 14-16). All text was in black font.

Participants were instructed to rate how acceptable each sentence sounds if the bolded and underlined expressions refer to the same person or thing, using a five-point scale $(1=$ completely unacceptable, $5=$ completely acceptable). Gordon and Hendrick (1997) successfully used this kind of method (both with binary yes/no responses and with a six-point scale) for probing acceptability of coreference when investigating people's judgements of Binding Principles A and B. In subsequent work, Keller and Asudeh (2001) set out to replicate some of Gordon and Hendrick's results using a similar method, except with the critical words presented in capitals rather than bold font, and using Magnitude Estimation rather than a binary yes/no acceptability response or a Likert-scale type response. They

\footnotetext{
${ }^{7}$ Gordon and Hendrick (1997) used bold font without underlining. Keller and Asudeh (2001) showed that using words in ALL CAPITALS without bold font also works (see also Collins et al. 2009 on using + before and after words, e.g. +herself + ). We used both bold font and underlining (but no capitals) because on some modern fonts, boldface by itself is not very distinctive. We wanted to ensure that there was no confusion about which words were bolded and underlined.
} 
successfully replicated Gordon and Hendrick's results, further confirming that this kind of task can be successfully used to test coreference judgements in an experimental setting.

In our study, before the main experiment, the experimenter discussed a series of example items with the participant, to ensure that participants understand the task. Participants were also told that a colloquial tone/register should not be interpreted as unacceptable, because we did not want the informal tone of child-directed speech to be judged negatively. In addition, to ensure that the first-person "I" or "we" in the preambles is interpreted as intended, we also included example items which showed that in sentences with three bolded and underlined words, participants should consider all three and should only rate a sentence as acceptable if all three can refer to the same person or thing.

The filler items in the study were designed so that in some, the bolded and underlined words were coreferential (expected rating on the five-point scale is high); in others, the bolded and underlined words could not corefer (expected rating is low); and in some others, the bolded and underlined words could be construed as coreferential but did not need to be. This was done to prevent participants from developing a response strategy or a default bias for one kind of response.

\subsection{Predictions}

According to the syntactic view, both the local and the ultimate (AUTHOR) antecedent are syntactically equally available to antecede the possessive pronoun. Thus, the discourse salience/prominence of the speaker/ultimate antecedent is not expected to have any effect on pronominal agreement, and both third-person and first-person pronouns are predicted to be equally acceptable, at least with plural imposters. Thus, under this view, (i) the presence/absence of the preamble clause is not expected to influence acceptability judgements, and (ii) the pronoun manipulation (first vs. third person) is also not expected to influence acceptability of plural imposters. The situation is less clear for singular imposters: Collins and Postal (2012) judge singular imposters to be ungrammatical with first person pronouns, but others disagree. Thus, it is not clear whether we should expect an interaction between number and pronoun person.

According to the notional view, imposters are syntactically normal third-person DPs and their special referential behavior stem from their semantic or pragmatic properties. Under this approach, one might well find that in a context where the first-person AUTHOR (the speaker of the sentence) is very prominent, due to having been recently mentioned in subject position with a first-person pronoun, we may find that first-person pronouns are judged to be more acceptable than in a context where the AUTHOR is less prominent. In other words, we may find an interaction between presence/absence of preamble clause and whether the pronoun is first or third person: The third-person pronoun will (presumably) be acceptable in all contexts, as it matches the 'surface form' of the imposter, whereas the first-person pronoun may be more acceptable in the presence of the AUTHOR-boosting preamble clause. It is important to acknowledge that the notional view does not explicitly predict an effect of the presence/absence of the AUTHOR-mentioning preamble clause, but would be more compatible with such a finding than the syntactic view would. As regards potential 
differences between plural vs. singular imposters, the notional view (at least a simple version thereof) does not straightforwardly lead us to expect any differences based on number.

\section{Results and discussion}

Figure 1 shows the average acceptability ratings for each of the eight conditions. The data were analyzed using mixed-effect regression models (lmer, R, R Core Team, http://www.Rproject.org/). Following a widespread convention, effects are reported as significant when $|\mathrm{t}|$ $\geq 2$.

\section{Ratings ( $1=$ completely unacceptable, $5=$ completely acceptable)}

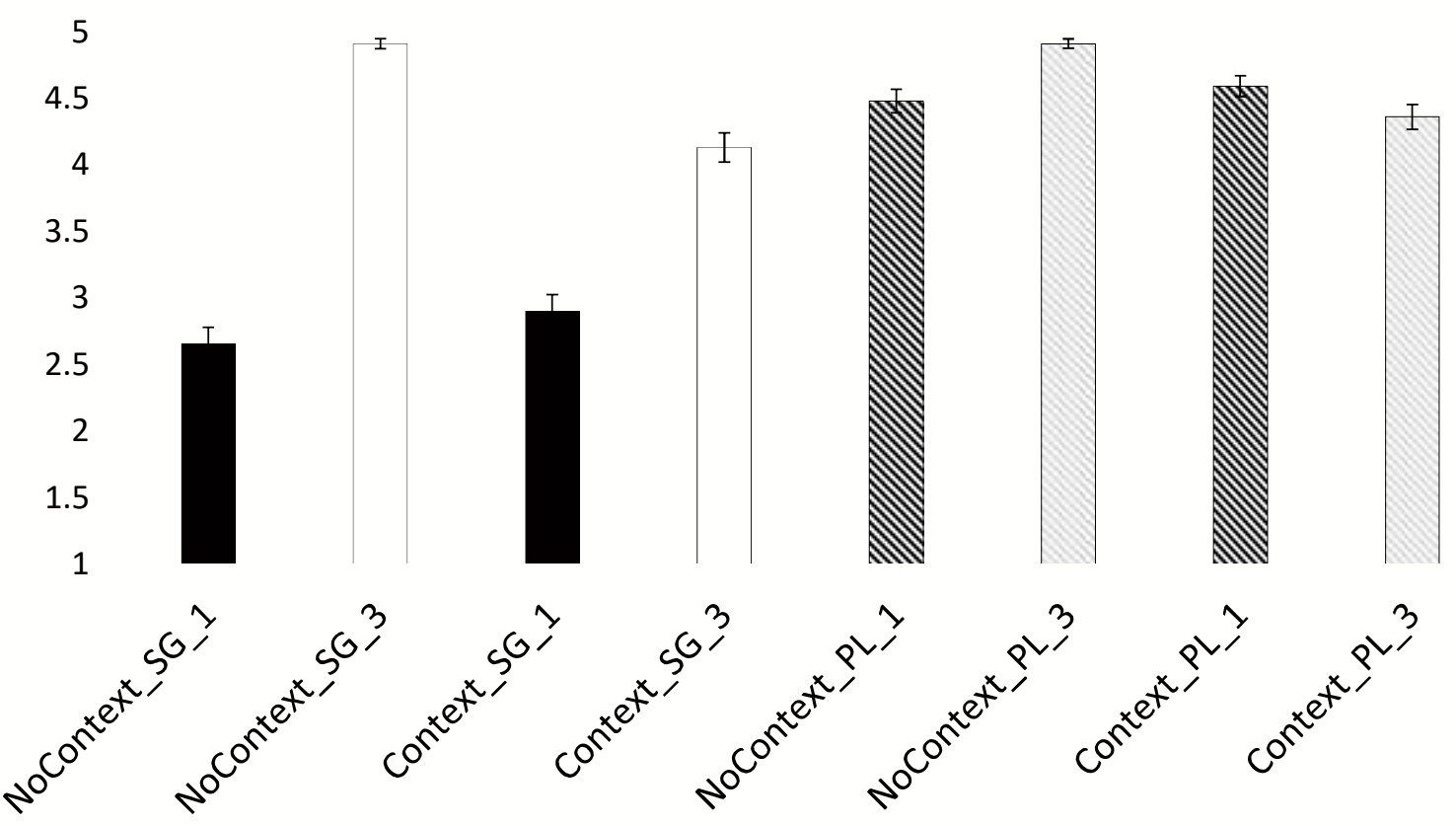

Figure 1. Mean acceptability ratings in each condition, based on a five-point scale (1=completely unacceptable, $5=$ completely acceptable. Error bars show $+/-1$ SE.

\subsection{Singular imposters: Comparing first- and third-person pronouns}

Let us first consider the left half of the figure, which shows the conditions with singular imposters (with singular first- or third-person pronouns). Conditions with third-person pronouns are rated significantly more acceptable than conditions with first-person pronouns: More specifically, Context_SG_3 is rated significantly more acceptable than Context_SG_1, and NoContext_SG_3 is rated significantly more acceptable than NoContext_SG_1. This shows that, both with and without an AUTHOR-boosting preamble clause, people significantly prefer third-person pronouns with singular imposters over first-person pronouns.

One of the questions we posed at the start of the paper is whether first-person pronouns are acceptable with imposter antecedents or not. It is important to keep in mind that a five-point scale does not allow us to directly determine whether a certain sentence is grammatical or 
ungrammatical. Although sentences with singular imposters that antecede first-person pronouns are judged less grammatical than the third-person variants, their average ratings are nevertheless between 2.5 and 3 on the five-point scale (as can be seen in the figure), and thus around the midpoint of the scale (3). A five-point scale does not allow us to identify specific cut-offs for grammatical vs. ungrammatical sentences, but the fact that our study yielded ratings near the mid-point of the scale-as opposed to ratings averaging around 1-suggests that first-person pronouns anteceded by imposters are not strikingly ungrammatical but are significantly less acceptable/less grammatical than third-person pronouns.

As a whole, these findings are in line with the intuitions, reported in prior work, that thirdperson pronouns are the default option for singular imposters in English, and that first-person pronouns are more marked.

\subsection{Plural imposters: Comparing first- and third-person pronouns}

Turning now to the right half of the figure, which shows the conditions with plural imposters, it is immediately clear that overall ratings are relatively high in all plural-pronoun conditions: All means are 4 or higher, on the five-point scale. Statistical analyses show that the Context_PL_3 and Context_PL_1 conditions do not differ significantly from each other: With an AUTHOR-boosting preamble clause that mentions 'we', sentences where an imposter antecedes 'our' are rated equally acceptable as sentences with 'their'. Thus, the first vs. third person asymmetry observed with singular imposters is absent here.

In conditions with no preamble clause, we find that NoContext_PL_3 is rated as significantly more acceptable than NoContext_PL_1 $(|t|>2.8)$. We say more about this below. For now, suffice it to say that in the NoContext condition, sentences where the pronoun agrees with the local, linguistically overt antecedent (third person) are rated as significantly more acceptable than sentences where the pronoun agrees with the ultimate AUTHOR antecedent (first person).

\subsection{Effects of the AUTHOR-boosting context manipulation?}

What about effects of context? Here, our specific question concerns the conditions with firstperson pronouns, because we want find out whether the presence of an AUTHOR-boosting preamble sentence improves the acceptability of first-person pronouns with imposters. Acceptability of third-person pronouns is not under debate (as prior work agrees that English imposters can antecede third-person pronouns). We also do not expect acceptability of third person pronouns to benefit from the presence of a first-person/AUTHOR-boosting context.

With singular imposters and first-person pronouns, we find no effects of the context manipulation: The presence of an AUTHOR-boosting preamble clause does not make sentences with first-person pronouns significantly more acceptable than their contextless counterparts (Context_SG_1 and NoContext_SG_1), though-intriguingly-the effect is numerically in the right direction. Context $\mathrm{SG}_{-} 1$ is rated numerically as more acceptable than NoContext_SG_1 $(\mathrm{t}=1.845$, where $|\mathrm{t}|=2$ is widely viewed as the minimum threshold for 
significance). Despite these hints of a potential context boost, the conditions with first-person singular pronouns receive the lowest ratings out of all eight conditions.

With plural imposters and first-person plural pronouns (Context_PL_1 and NoContext_PL_1), statistical analyses show no effect of the context manipulation, which is expected based on the patterns in Figure 1: Both conditions receive ratings around 4.5, regardless of the presence or absence of the AUTHOR-boosting clause.

What about sentences with third-person pronouns? Recall that the third-person conditions are not crucial to our AUTHOR-boosting hypothesis, which focuses on the acceptability of firstperson pronouns. Nevertheless, if we look at how the presence/absence of the preamble clause influences sentences with third-person pronouns, statistical analyses reveal that with both singular and plural imposters, we find that sentences with (singular or plural) thirdperson pronouns are rated higher in the NoContext than Context conditions $(|t| ' s>3)$. This is presumably because the Context conditions with the AUTHOR-boosting preamble clause with the first person pronoun "we" involve a clash between the first-person pronoun in the preamble clause and the third-person pronoun in the second clause, which decreases acceptability.

Overall, the presence of an AUTHOR-mentioning preamble clause does not increase acceptability in any condition: Either we find no significant effects (with singular imposters) or we find effects in the opposite direction (with plural imposters).

\subsection{Implications for theoretical accounts of imposters}

The finding that explicit mention of the AUTHOR by means of a subject-position first-person singular or plural pronoun does not boost the acceptability of first-person pronouns with imposter antecedents goes against the hypothesis we formulated on the basis of the notional view and existing work on reference resolution.

However, other aspects of our results pose challenges for the syntactic view. One challenge comes from the finding that in plural pronoun conditions without a context clause, the linguistically overt third-person antecedent is the preferred target for agreement-i.e., sentences with third person possessive pronouns are rated as more acceptable than sentences with first person possessive pronouns. This is unexpected under the syntactic view, which posits that both the first person AUTHOR (ultimate antecedent) and the third person immediate antecedent are available. Indeed, the finding that the linguistically local, overt antecedent is preferred over the covert, notional antecedent-which, according to Collins and Postal (2012), is represented by a null DP in the left periphery-suggests that processing factors related to locality (the ultimate AUTHOR antecedent is less local) as well as overtness (the AUTHOR DP is not linguistically overt) may be at play. This suggests that a purely syntactic approach by itself is likely to be insufficient. Broadly speaking, locality-based effects are widely observed in different domains of language processing, and prior work has also found that different referring forms have consequences for the subsequent prominence of their referents, so it would not be surprising to find similar effects here. 
Furthermore, another potential challenge for a purely syntactic approach to imposter agreement comes from the finding that in conditions with a preamble mentioning the firstperson AUTHOR by means of "we", use of the third-person pronoun "their" elicits lower acceptability ratings than use of first-person "our". We suggest that this may be due to the person mismatch between "we" and "their": In a context where a first-person pronoun has been established (by the preamble) as the discoursally-preferred means of referring to the imposter, switching to a third-person pronoun is dispreferred-even though the third-person pronoun matches the 'surface form' of the imposter. Under a purely syntactic account, something more would need to be said in order to explain how such a person clash would impact acceptability, given that both first- and third-person antecedents are available for the possessive pronoun to agree with.

\section{Conclusions}

In this paper, we investigated the agreement properties of imposters-expressions that are grammatically third-person but are used to refer to the first-person speaker or the secondperson addressee (e.g. Mommy' or 'Daddy' when used by parents for first-person selfreference in child-directed speech). Current analyses of imposters differ in whether they derive the referential properties of imposters using syntactic means (the syntactic view) or attribute them to semantic and pragmatics (the notional view).

In this paper, we took some initial steps to shed light on these competing approaches by means of a psycholinguistic experiment, focusing on first-person imposters. We tested the acceptability of first-person vs. third-person pronouns used to refer to singular and plural imposter antecedents, and also manipulated the discourse accessibility of the first-person speaker by means of a preamble clause.

We tested whether boosting the prominence of the first-person AUTHOR (speaker of the sentence) by explicit mention by means of "I" or "we" makes subsequent first-person pronouns more acceptable with imposter antecedents. A purely syntactic view of imposters does not directly lead us to expect any effects of this prominence-boosting approach. In contrast, although prominence/accessibility is not explicitly discussed by prior proponents of the notional view, potential, prominence-boosting effects would be compatible with that approach.

Our results suggest that manipulating the prominence of the first-person speaker does not significantly boost the acceptability of first-person pronouns in imposter-referring contexts, although we observe hints of numerical effects in the predicted direction with singular imposters. Furthermore, our results suggest that a purely syntactic approach may not be sufficient either, as psycholinguistic processing factors related to locality and the null/overt distinction also appear to be relevant. However, further work is necessary to better understand the effects, and this is an important direction for future work. In light of prior psycholinguistic work on locality effects and consequences of referential form for referent prominence, our findings point to a close interplay between processing factors and syntactic representations. 


\section{References}

Akkuş, F. (2017). Agreement and Anaphora in the context of Imposters. In A. Kaplan et al. (eds.), Proceedings of the 34th West Coast Conference on Formal Linguistics, pp. 24-31. Somerville, MA: Cascadilla Proceedings Project.

Ariel, M. (1990). Accessing noun phrase antecedents. London: Routledge.

Baker, M. (2008). The Syntax of Agreement and Concord. Cambridge, England, Cambridge University Press.

Brennan, S. E., M.A. Friedman and C.J. Pollard. (1987). A centering approach to pronouns. In Proceedings of the 25th annual meeting of the Association for Computational Linguistics, 155-162. Stanford, CA: Association for Computational Linguistics.

Collins C., S. Moody and P. Postal (2008). An AAE camouflage construction. Language 84: 29-68

Collins, C. and P. Postal. (2012). Imposters. MIT Press, Cambridge, MA.

Collins, C. (2014). Cross-Linguistic Studies of Imposters and Pronominal Agreement (editor). Oxford Studies in Comparative Syntax.

Collins, C., S. Guitard and J. Wood (2009). Imposters: An Online Survey of Grammaticality Judgments. NYU Working Papers in Linguistics, Volume 2: Papers in Syntax, Spring 2009

Givón, T. (1983). Topic continuity in discourse: A quantitative cross-language study. Amsterdam and Philadelphia: Benjamins.

Gordon, P. C., and R. Hendrick, (1997). Intuitive knowledge of linguistic co-reference. Cognition, 62, 325-370.

Gundel, J. N. Hedberg and R. Zacharski. (1993). Cognitive status and form of referring expressions in discourse. Language 69(2). 274-307.

Gärtner, H.-M. and M. Steinbach. (2006). A Skeptical Note on the Syntax of Speech Acts and Point of View. In P. Brandt and E. Fuß (eds), Form, Structure, Grammar, pp. 213-22. Berlin: Akademie Verlag.

Haegeman, L. and V.Hill. (2013). The syntacticization of discourse. In R. Folli, C. Sevdali and R. Truswell. (eds), Syntax and its limits, pp. 370-390. Oxford University Press, Oxford, UK.

Keller, F. and A. Asudeh. (2001). Constraints on linguistic coreference: Structural vs. pragmatic factors. In J.D. Moore and K. Stenning, Proceedings of the 23rd Annual Conference of the Cognitive Science Society, pp. 483-488. Mahawah, NJ: Lawrence Erlbaum

Podobryaev, A. (2014). Persons, Imposters, and Monsters. PhD dissertation, MIT

Podobryaev, A. (2017). Three routes to person indexicality. Natural Language Semantics 25:329-354

Rizzi, L. (1997). The Fine Structure of the Left Periphery. In L. Haegeman (ed.), Elements of Grammar: A Handbook of Generative Syntax, pp. 281-337. Dordrecht: Kluwer.

Ross, J.R. (1970). On Declarative Sentences. In R. A. Jacobs and Peter S. Rosenbaum (eds.), Readings in English Transformational grammar. Waltham, Mass.: Ginn.

Siewierska, A. (2004). Person. Cambridge, England. Cambridge University Press.

Speas, M. and Tenny, C. (2003). Configurational properties of point of view roles. In A.M. DiSciullo (ed.), Asymmetry in grammar, pp. 315-344. John Benjamins, Amsterdam, The Netherlands.

Stirling, L. and R. Huddleston. (2002). Deixis and Anaphora. In R. Huddleston and G.K. Pullum (eds.), The Cambridge Grammar of the English Language, 1449-1564. Cambridge, England. Cambridge University Press. 